\title{
CAPÍTULO 24: PLANEJAMENTO ESTRATÉGICO EM UMA EMPRESA DE ARMAZENAGEM DE GRÃOS NO MUNICÍPIO DE AMAMBAI - MATO GROSSO DO SUL
}

\section{CAPÍTULO 24: PLANIFICACIÓN ESTRATÉGICA EN UNA EMPRESA DE ALMACENAMIENTO DE GRANOS EN LA CIUDAD DE AMAMBAI - MATO GROSSO DO SUL}

\section{CHAPTER 24: STRATEGIC PLANNING IN A GRAIN STORAGE COMPANY IN AMAMBAI CITY - MATO GROSSO DO SUL}

\begin{abstract}
Deisivani Carol Lima dos Santos ${ }^{1}$; André Felipe Queiroz ${ }^{2}$; Lesley Soares Boeno ${ }^{3}$; Valéria Sun Hwa Mazucato ${ }^{4}$
\end{abstract}
DOI: $\underline{\text { https://doi.org/10.31692/978-65-88970-17-1.350-366 }}$

\begin{abstract}
RESUMO
A armazenagem de grãos é um importante elo da cadeia produtiva agrícola, que representa um nicho de crescentes oportunidades no qual o agronegócio tem sido extremamente favorecido pelo potencial produtivos das regiões em que se localiza, contexto este que tem implicao ao planejamento estratégico um papel cada vez maisimportante na gestão de empresas armazenadoras de grãos. Com o intuito de contribuir com essa área de estudos, este trabalho assume como objetivo geral avaliar estrategicamente o ambiente organizacional e o posicionamento competitivo de uma empresa de armazenagens de grãos localizada no município de Amambai no mato Grosso do Sul, a partir da análise do ambiente interno e externo (Matriz Swot) da organização e a Análise das 5 Forças de Porter. A metodologia adotada foi um estudo de caso, com coleta de dados por entrevista estruturada, observação in locco e análise documental, sendo que todos os dados coletados foram analisados conforme a proposta das ferramentas escolhidas. A Análise de 5 forças de Porter permitiu constatar que apesar da grande concorrência na região, a empresa se destaca frente a seus concorrentes, possuindo grande potencial de crescimento no mercado, embora existam ameaças importantes a serem observadas. A Matriz Swot evidenciou os aspectos positivos se sobressaem aos negativos, sendo favorável a manutenção da estratégia adorada atualmente pela empresa, que se caracterizou como de crescimento, porque é a que mais se enquadra ao posicionamento competitivo atual da empresa, sua relação com os concorrentes, clientes e demais stakeholders e, principalmente, ao cenário local do agronegócio que apresenta imporantes oportunidades.
\end{abstract}

Palavras-chave: Agronegócio. Planejamento Estratégico. Matriz Swot. 5 forças de Porter.

\section{RESUMÉN}

El almacenamiento de granos es un eslabón importante en la cadena productiva agrícola, que representa un nicho de oportunidades de crecimiento en el que la agroindustria se ha visto sumamente favorecida por el potencial productivo de las regiones en las que se ubica, contexto que tiene un papel cada vez más importante en la planificación estratégica. .más importante en la gestión de empresas de almacenamiento de cereales. Para contribuir a esta área de estudio, este trabajo asume como objetivo general evaluar estratégicamente el ambiente organizacional y posicionamiento competitivo de una empresa almacenadora de granos ubicada en el municipio de Amambai en Mato Grosso do Sul, a partir del análisis de el entorno interno y externo (Matriz FODA) de la organización y el Análisis de las 5 Fuerzas de Porter. La metodología adoptada fue un estudio de caso, con recolección de datos a través de entrevistas estructuradas, observación in situ y análisis de documentos, y todos los datos recolectados

\footnotetext{
${ }^{1}$ Curso Superior de Tecnologia em Gestão do Agronegócio, IFMS, deisivanisantos@ gmail.com

${ }^{2}$ Professor Mestre IFMS, andre.queiroz@ifms.edu.br

${ }^{3}$ Professor Doutor IFMS, lesley.bueno@ifms.edu.br

${ }^{4}$ Professora Mestre em Administração, IFMS, valeria.galvao@ifms.edu.br
} 


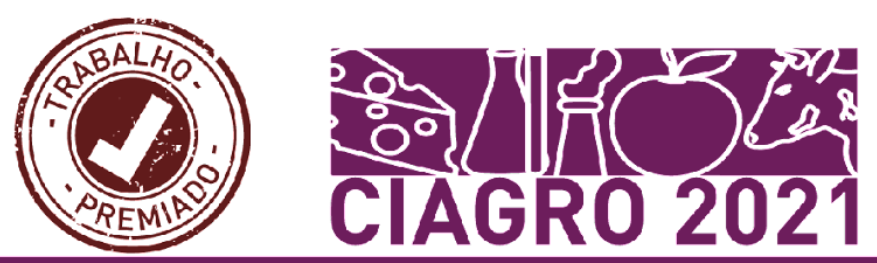

fueron analizados de acuerdo a la propuesta de las herramientas elegidas. El Análisis de Porter de 5 Fuerzas mostró que a pesar de la gran competencia en la región, la empresa se destaca frente a sus competidores, teniendo un gran potencial de crecimiento en el mercado, aunque existen importantes amenazas por observar. La Matriz FODA destacó los aspectos positivos que se destacan de los negativos, favoreciendo el mantenimiento de la estrategia actualmente amada por la empresa, la cual se caracterizó como crecimiento, por ser la que mejor encaja con la actual posición competitiva de la empresa, su relación con los competidores. , clientes y otros grupos de interés y, principalmente, al escenario agroindustrial local que presenta importantes oportunidades.

Palabras clave: Agronegocios. Planificación estratégica. Matriz Swat. 5 fuerzas de Porter.

\section{Abstract}

Grain storage is an important link in the agricultural production chain that represents a niche of growing opportunities in which agribusiness has been extremely favored by the productive potential of the regions in which it is located, a context that has implications for strategic planning, an increasingly important role. important in the management of grain storage companies. In order to contribute to this area of study, this work assumes as a general internal objective to strategically evaluate the organizational environment and the competitive positioning of a grain storage company located in the municipality of Amambai in Mato Grosso do Sul, from the analysis of the environment and external (Swot Matrix) of the organization and the Analysis of Porter's 5 Forces. The adopted methodology was a case study, with data collection by structured interview, observation in locco and document analysis, and all the data collected were according to the proposed tools chosen. The analysis of the common Porter's window shows that despite the great competition in the region, the company stands out against its competitors, having great potential for growth in the market, although there are important ones to be observed. The Swot Matrix highlighted the positive aspects that outweigh the negative, favoring the maintenance of the strategy currently adored by the company, which was characterized as growth, because it is the one that best fits the current competitive positioning of the company, its relationship with competitors, customers and other stakeholders and, mainly, to the local agribusiness scenario that presents important opportunities.

Keywords: Agribusiness. Strategic planning. Swot Matrix. Porter's5 forces.

\section{INTRODUÇÃO}

O planejamento estratégico é primordial para a definição das estratégias organizacionaise modelos adequados de gestão para que uma determinada empresa alcance seus objetivos. Especialmente no agronegócio, que sofre de forma acentuada os impactos de situações inesperadas, visto a dependência do clima e da perecibilidade de seus produtos, o planejamento estratégico assume um papel muito importante.

Nas empresas de armazenamento de grãos, por exemplo, o planejamento estratégico se expressa na delimitação dos objetivos organizacionais sim, mas além disso, também é percebido nas atividades cotidianas, responsáveis por garantir a qualidade dos serviços prestados e do produto final vendido. É de extrema importância o gerenciamento de qualidade na rede de armazenagem, sabendo então, para que o produto armazenado chegue ao consumidor com as 


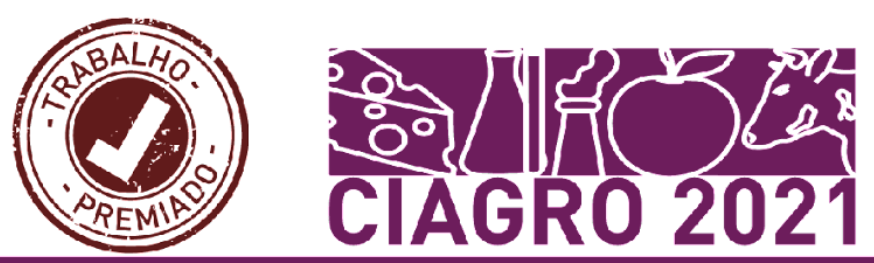

devidas exigências padrões de qualidade, e que não perca produto com má gestão é necessário que sejam adotados métodos para que tenha menor custo e obtenha um melhor resultado.

Devido a esta importância, tem se tornado cada vez mais numerosos os trabalhos publicanos na área da gestão estratégica, inclusive voltados para o agronegócio (POLACINSKI et al., 2021; COSTA et al., 2020; GASPERIN, 2017; SOUZA et al., 2017). Soares et al (2016), por exemplo, discutiram em seu estudo, a viabilidade econômica de trabalhar no setor de apicultura. Seus resultados indicaram que planejamento estratégico é um fator determinante para a saúde e sustentabilidade dos negócios. Silva (2018), por sua vez, estudou como demonstrar a viabilidade do planejamento estratégico em pequenas propriedades rurais e constatou que a falta de planejamento e uso de ferramentas de gestão podem trazer a ineficiência de produtividade. Ele também concluiu que por meio da implantação planejamento estratégico, foi possível aumentar cerca de $70 \%$ da produtividade.

Outros tantos trabalhos tem se dedicado a compreender como o planejamento estratégico contribui na prática das empresas. Ainda assim há uma enorme lacuna para a compreensão de como as peculiaridades de cada empresa interferem no planejamento estratégico e suas etapas, bem como seus resultados. Especialmente na armazenagem de grãos, são escassos os estudos na área de planejamento estratégico. Para contribuir com este ramo do conhecimento, este trabalho tem como objetivo geral avaliar estrategicamente o ambiente organizacional e o posicionamento competitivo de uma empresa de armazenagens de grãos localizada no município de Amambai em Mato Grosso do Sul.

\section{FUNDAMENTAÇÃO TEÓRICA}

\section{O Planejamento Estratégico}

O planejamento estratégico nas organizações tem como objetivo principal moldar os negócios e produtos de uma empresa, de modo que eles possibilitem os lucros e o crescimento almejados (KOTLER, 2000). Barros (2012) afirma que diante desta ferramenta de gestão, as organizações conseguem atingir uma percepção melhorada, assim podendo alcançar um possível crescimento econômico e financeiro.

Entre os diversos modelos didáticos de planejamento estratégico, o proposto por Chiavenato (2007) contempla seis principais etapas que estão apresentadas na figura 1. Partindo da identidade da empresa, a primeira etapa é a definição dos objetivos, partindo então para a analisar o ambiente externo, evidenciando fatores que possam influenciar nas tomadas de decisões da organização. 
A análise de ambiente externo é basicamente observar em qual cenário atual em que a empresa se encontra ou em qual posicionamento comercial estratégico ela atua, isso facilitará para qualquer tomada de decisão. Já a análise interna consiste no diagnóstico de aspectos como cultura e clima organizacional, qualidade dos produtos, organização das pessoas, entre outros, visa obter um diagnóstico de como é o funcionamento da empresa, quais pontos específicos devem ser melhorados ou corrigidos.

Figura 1: Etapas do Planejamento Estratégico.

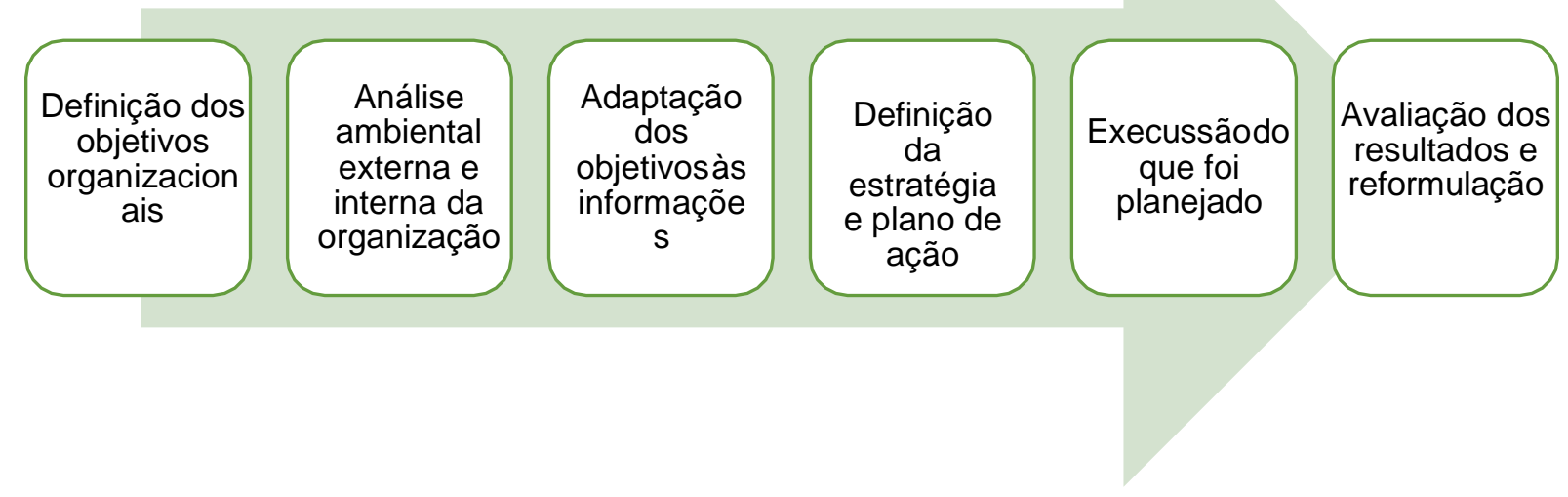

Fonte: Adaptado de Chiavenato (2007).

Com base na análise do ambiente organizacional, se dá a próxima etapa que é a adaptação dos objetivos diante o cenário do ambiente externo, e interno. A quarta etapa é o estudo de como será implantado o plano de ação, quais estratégias serão necessárias adotar para o cenário atual que a organização se encontra. Na etapa seguinte é a fase onde seráconstruído todo o plano de ação e por fim tem-se a avaliação dos resultados, através da avaliaçãopode ser determinado se houve êxito nos resultados desejados.

\section{Matriz Swot: Uma ferramenta de análise do ambiente organizacional}

Ao decorrer da evolução do planejamento estratégico como área de estudo, diversos especialistas acadêmicos e gerenciais observaram a aplicação do planejamento estratégico nas empresas e desenvolveram diversas ferramentas para auxiliar cada uma das etapas deste processo. Especialmente a etapa de análise do ambiente interno e externo da organização tem sido foco de diversas ferramentas, dentre as quais uma das mais conhecidas é a Matriz Swot.

A Matriz Swot foi criada pelo pesquisador Albert Humphrey, o qual liderou um projeto de pesquisa na universidade de Stanford responsável por cruzar dados das maiores corporações da época. A ferramenta desenvolvida pela pesquisa logo se tornou conhecida e utilizada por 


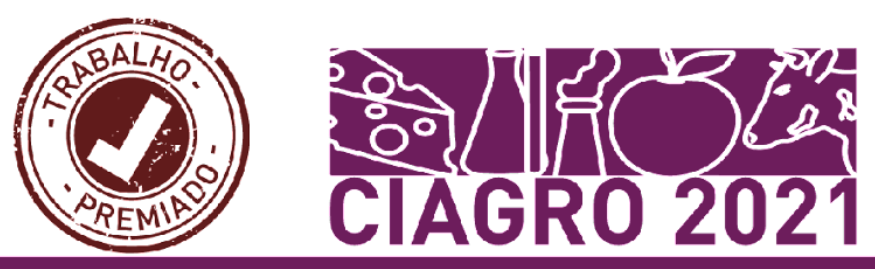

varias empresas para auxiliar nas elaborações de suas estratégias, por conseguir simplificar o diagnóstico da situação organizacional.

A Matriz Swot estuda o ambiente interno e externo de uma organização a partir de quatro elementos, sendo eles: Strengths (Forças), Weaknesses (Fraquezas), Oportunities (Oportunidades) e Threats (Ameaças). Por meio deles se obtém a Matriz Swot ( $\mathrm{S}$ - trengths; $\mathrm{W}$ - eaknesses; $\mathrm{O}$ - portunities; $\mathrm{T}$ - hreats).

Também conhecida como Análise Swot, esta ferramenta é cada vez mais utilizada em grande escala pelas organizações. Contudo é uma ferramenta simples, que traz grandes resultados quando aplicada, ela visa situar em qual posição tática a empresa ou organização está, entretanto evidencia os pontos fortes e fracos, internos e externos da instituição. Para Serra et al. (2004, p. 28) "a função primordial da Matriz Swot é possibilitar a escolha de uma estratégia adequada, para que se alcancem determinados objetivos, a partir de uma avaliação crítica dos ambientes internos e externos".

Para Chiavenato (2007), a Matriz Swot constitui a ideia de junção entre a análise ambiental e a análise da organização, para analisar a condição da instituição em um certo período de tempo. O confronto da análise de ambiente externo e interno, possibilita a visão e desenvolvimento de estratégias que possam melhorar, e desenvolver suas vantagens competitivas, ou até mesmo diminuir os contrastes de suas deficiências internas e intervenções externas.

No agronegócio, a Matriz Swot tem sido intensamente utilizada para análises estratégicas e tomadas de decisões (POLACINSKI et al., 2021; COSTA et al., 2020). Gasperin (2017), por exemplo, aplicou esta ferramenta para diagnosticar o ambiente interno e externo em propriedades rurais familiares no Rio Grande do Sul, como forma de analisar os custos de transação e os recursos estratégicos e, consequentemente, identificar os aspectos de impacto competitivo a estes produtores.

Souza et al. (2017) fizeram uso da Matriz Swot para diagnosticar o cenário do agronegócio de Santa Catarina como forma de blindar a proposta de uma nova empresa contra possíveis ameaças. Neste caso específico a Matriz Swot fez parte do planejamento estratégico de abertura da empresa. Já Behnen (2020) utilizou Matriz Swot para avaliar a gestão de custos do plantio de grãos de uma propriedade rural, enquanto que Costa et al. (2020) aplica a Matriz Swot como parte da análise da utilização de sistemas de gerenciamento de armazéns no Agronegócio do Distrito Federal, e sua relação com os Condomínios de Armazéns Rurais.

Nota-se que, no contexto que se refere ao agronegócio, a aplicação da Matriz Swot tem permitido a diagnósticos interessantes, que contribuíram para a melhor tomada de decisão por 


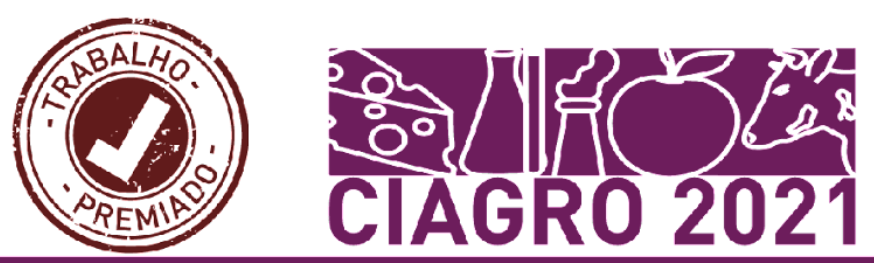

parte dos gestores. Percebeu-se também a preocupação em explicitar as evidências analisadas, de forma que a tomada de decisão seja embasada em circunstâncias e fatos corretos.

\section{A Análise das 5 Forças de Porter}

A Análise das 5 forças de Porter podem ser definidas como uma ferramenta de análise ambiental, que pode ser utilizada como complemento à Matriz Swot ou em análises singulares. A Análise das 5 Forças de Porter tem o objetivo de ajudar a análise do ambiente organizacional que está inserido, assim obtendo estratégias eficazes que colaboram com o crescimento da mesma (PORTER, 2004). Para Proença (1999), o foco desta ferramenta consiste em detectar quem está com vantagem e porquê. Pode ainda resolver os problemas verticais da empresa, sua forma e direção.

A Análise das 5 forças de Porter contempla cinco dimensões de análise, sendo elas os clientes, os concorrentes, os produtos substitutos, os fornecedores e a ameaça de novos entrantes no mercado de atuação da empresa.

Os produtos substitutos são aqueles que possuem como principal característica desempenhar a mesma função que o produto ou serviço oferecido possui (SERTEK et al., 2007). Porter (2004) diz que os produtos substitutos é um meio de limitação da lucratividade, pois quanto mais atrativo e de menor valor do produto, consequentemente maior será a ameaça sobre os preços ofertados pela empresa. A ameaça de entrada de novos concorrentes observa quais são as chances de novos concorrentes no mercado em qual atua, qual as chances de crescimento e lucratividade. O poder de negociação dos clientes, refere-se à capacidade do cliente em barganhar maneiras de pagamentos. O poder de negociação dos fornecedores, trata-se da empresa onde contrata seus fornecedores, negociar prazos e preços, onde a organização que depende desses serviços, fica à mercê de seus provedores, e por fim a rivalidade entre os concorrentes, visa destacar que por mais que um mercado que possua muitas empresasprestando o mesmo serviço a rivalidade e concorrência será maior.

No contexto do agronegócio esta ferramenta tem sido aplicada em diversas análises sobre vantagem competitiva, como é o caso de Coutinho e Chaves (2009) que aplicaram a Análise das 5 Forças de Porter como parte de um sistema de informações do mercado proposto ao produtor de arroz, ou Pedrozo et al. (2005) que a aplicaram para avaliar o ambiente de negócio, a estrutura competitiva e o comportamento estratégico da agroindústria avícola.

Mattos et al (2010) utilizaram a Análise das 5 Forças de Porter como ferramenta para diagnóstico estratégico nas unidades de produção primária, o qual obteve como resultado 


\section{significativo a identificação do cenário das empresas estudadas, com predominância de pontos}

fortes e oportunidades para a propriedade rural estudada. Martinez (2020), por sua vez, buscou estender a proposição de forças competitivas no agronegócio incluindo as questões da sustentabilidade.

\section{Estratégias organizacionais}

As estratégias organizacionais consistem no ato de planejar e executar medidas para que a empresa alcance seus objetivos. Embora as estratégias organizacionais possam ser de incontáveis particularidades, dependendo da empresa, seus objetivos e cenário de atuação, neste trabalho serão consideradas as quatros principais vertentes de estratégias propostas por Oliveira (2007), que são de sobrevivência, manutenção, desenvolvimento e crescimento.

Estratégias de sobrevivência são aquelas em que a empresa opta pela redução de alguns custos e o desinvestimento. Normalmente é adotada quando uma determinada empresa passa por um momento de crise, seja por questões internas, seja por questões externas, como uma recessão econômica do país ou alteração do comportamento de compra de seus consumidores.

Na estratégia de manutenção, por sua vez, a empresa já alcançou patamar considerável e pretende manter sua posição no mercado, assim ela busca novas aberturas em especializações, dominando apenas uma área específica, assim valorizando seus pontos fortes.

A estratégia de crescimento é adotada quando a empresa possui caráter de ambiente externo comercial favorável, no entanto a empresa busca aliados de mercado, aproveita essas oportunidades para fazer algo novo, diversificação. Ela pode optar por fazer algo novo, lançar algum produto ou serviço que ainda não foi lançado, ou também poderá fazer transações comerciais, optando pela estratégia de exportar seus produtos ou serviços.

Também é bastante comum dentro da estratégia de crescimento, optar pela estratégia de joint venture, quando a empresa quer entrar em um outro ramo de mercado, então ela busca uma outra organização para ser aliada, onde cada uma colabora com um item necessário, seja ele tecnologia ou capital, para que seja produzido o produto. Ela pode também optar pela estratégia de expansão que deve ser planejada minunciosamente, pois a análise de mercado ter que ser criteriosa, pois a não expansão ou a expansão em momentos incertos pode lavar a possíveis perdas.

Por fim, a estratégia de desenvolvimento é utilizada quando ela possui características de pontos fortes e quer utiliza-las. Diante disso, ao que diz respeito a estratégia de desenvolvimento, essa técnica busca escolher um mercado que já atua comercialmente e tenta 
aperfeiçoar o serviço prestado, ou também usa de um produto ou serviço que já é destaque em sua linha comercial e leva para outro mercado.

\section{METODOLOGIA}

Em vista dos objetivos propostos, este trabalho se caracteriza como um estudo qualitativo de nível descritivo, que tem por objetivo a descrição das características de determinada população ou fenômeno ou, então, o estabelecimento de relações entre variáveis (GIL, 2002, p. 45). O delineamento adotado foi o de estudo de caso, no qual o objeto de estudo foi estudado de forma extensiva e aprofundada (Gil, 2002). Foram coletados dados por meio roteiro de entrevista estruturada com pessoas chave dentro da organização, totalizando três respondentes e contemplando o processo operacional da empresa. Foram também feitas investigações em documentos organizacionais e observação diária in locco ao longo dos meses de outubro a dezembro do ano de 2020.

Os dados provenientes das entrevistas e das anotações de campo foram analisados a partir do seu conteúdo, de acordo com as ferramentas escolhidas neste trabalho: a Matriz Swot e a Análise das 5 Forças de Porter. Dessa forma, foi possível a avaliação das características da empresa e do seu ambiente interno e externo, de forma a elucidar o cenário atual da empresa e evidenciar possíveis escolhas estratégicas mais vantajosas.

\section{RESULTADOS}

Os resultados do trabalho permitiram a caracterização do cenário competitivo da empea visto suas características estratégicas e seu ambiente interno e externo. Primeiramente destacase que, assim como o proposto na literatura, o planejamento estratégico partiu da identidade da empresa.

Averiguou-se então que a empresa objeto deste estudo é um armazém de grãos que pertencente a uma família que atua também com serviços de abatedor de bovinos, frigorifico, onde é fonte de renda de aproximadamente 200 famílias da região. Os proprietários da empresa atualmente se dedicam ao frigorífico que é localizado em frente ao armazém, deixando como responsável e filho mais novo do casal.

A empresa foi inaugurada em junho de 2019 e partir do sucesso alcançado nesta atividade os proprietários decidiram abrir em um futuro próximo, uma nova filial em um ponto 
estratégico. Até o momento da realização deste estudo e delimitando-se a análise apenas ao armazém já em funcionamento.

No que tange aos demais elementos da identidade organizacional, como missão, visão e valores, a organização ainda não possui elementos bem estabelecidos. Não foram constatadas declarações de missão, visão e valores aos funcionários ou aos clientes, refletindo a recém entrada no mercado e o pouco uso de ferramentas de gestão que fortaleçam a identidade organizacional.

\section{Processos e Operações da Empresa}

A empresa conta com oito funcionários, sendo que cinco deles trabalham no setor operacional e três no setor administrativo. Cabe ao gerente o contato com os clientes e as atividades de venda dos serviços, além da gestão dos colaboradores. Ao setor administrativo cabem as tarefas auxiliares à venda, como emissão de notas fiscais e gestão de documentos, bem como as atividades referentes a gestão de departamento pessoal. Já ao setor operacional da empresa cabe todo o processo de recebimento e gestão dos grãos, detalhado na figura 2.

Figura 2: Fluxograma do Recebimento dos Grãos na Empresa.

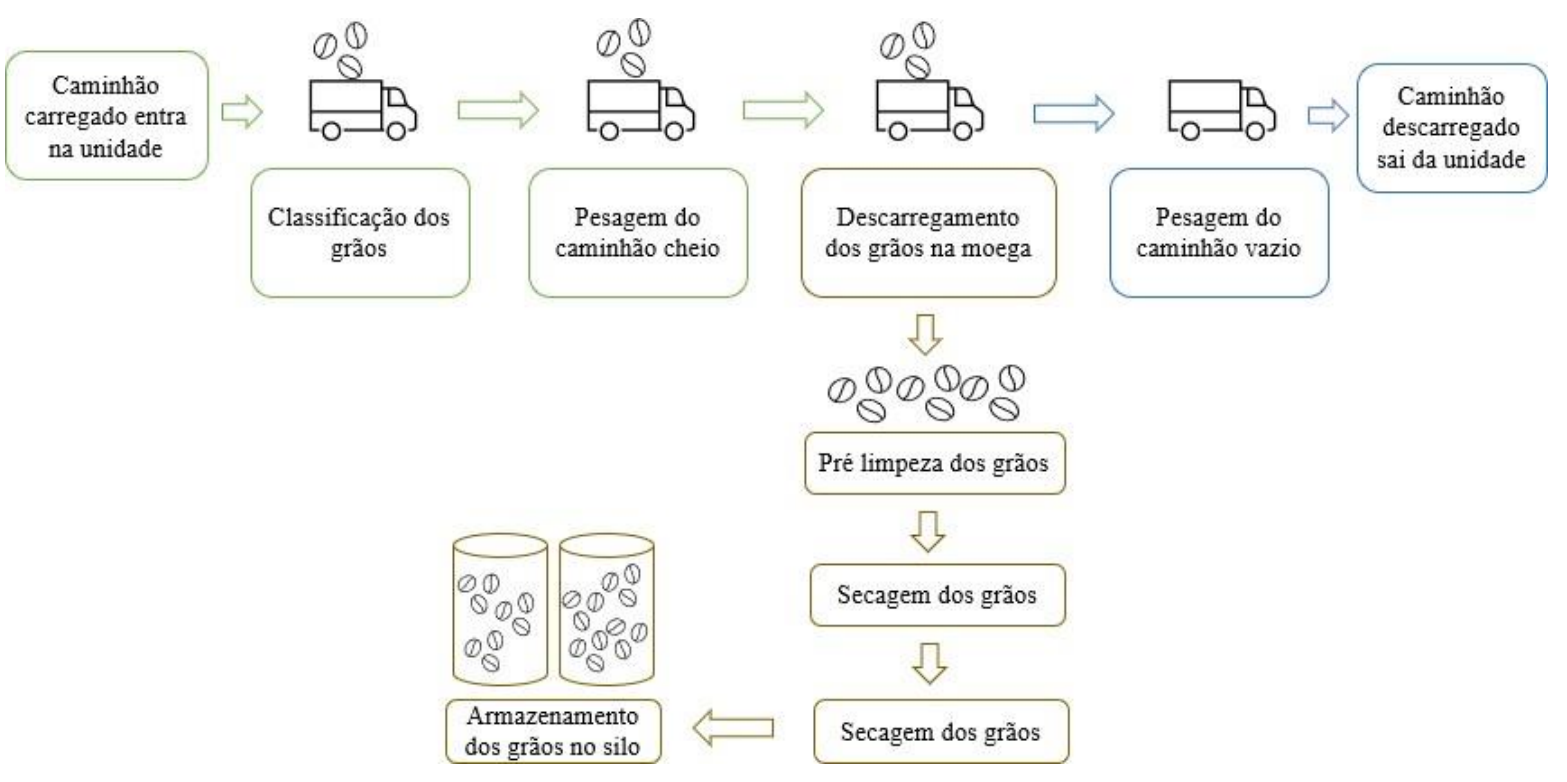

Fonte: Dados da pesquisa.

Como descrito pela figura 2, o caminhão contendo os grãos entra na unidade e os grãos passam por um processo de classificação, no qual o profissional classificador de cereais vai determinar a qualidade do produto e por meio desta classificação será possível determinar a melhor técnica de manejo necessário para aquela carga específica. 
Após esta primeira etapa, o caminhão carregado com o produto passa pela balança, para pesar o peso bruto, e segue para a moega onde vai descarregar o cereal. Para os grãos descarregados vem a etapa de pré-limpeza, secagem e limpeza do grão, onde na pré-limpeza e na limpeza provém os grãos quebrados, e aqueles grãos menores chamados também de resíduos, onde podem ser usados para o consumo animal.

Para realizar o processo de secagem de grãos, o produto passa primeiramente na prélimpeza e depois é submetido a secagem do grão onde esse produto é exposto a uma temperatura especifica até chegar à umidade desejada, após a secagem, o produto passa na limpeza, posteriormente à secagem pode haver algumas quebras devido o produto estar seco, por isso é necessário a temperatura ideal, depois de todo esse processo o produto é armazenado no silo.

No entanto o veículo volta novamente na balança e pesa vazio assim será possível saber a quantidade de produto que ele armazenou, através do peso e da classificação. De acordo com a qualidade dos grãos é feito uma porcentagem de descontos para o produto com umidade, impureza e outros requisitos de classificação acima do permitido, lembrando que o produto só será submetido a secagem se ele não estiver com umidade padrão estabelecido pelas normas do armazém. Ao serem armazenados a empresa é responsável por cobrar um valor, devido a prestação de serviço da mesma, porém esse valor só vai ser acertado no momento em que o cliente efetuar venda ou fazer retirada do produto estocado. Tendo em conta que as taxas de serviço correm mensalmente, para que seja designado um preço para a prestação de serviço é feito uma tabela com a porcentagem com o grau e valor que será cobrado por sacas.

A empresa opera com três taxas de prestação de serviços, a taxa de recebimento, taxa de armazenagem, e a quebra técnica que é a diferença da sobra do grão, todo armazém ou cooperativa tem um grau de porcentagem que define a quantidade que será descontado ao final da armazenagem do produto. Entretanto há também os descontos de impureza e umidade que tais são descontados no peso líquido do caminhão, se no entanto o caminhão obteve um peso x, com os descontos através de tabelas ele obterá um peso y, já descontado as impurezas e outros itens de classificação de acordo com a qualidade do produto, é descontado uma porcentagem tanto de impureza como de umidade e outros elementos se necessário, porém com descontos diferentes, não é usada a mesma tabela para obter a taxa de porcentagem da mesma. Essas tabelas podem variar de uma unidade armazenadora para outra, não são todas unificadas. 


\section{Discussão da Análise das 5 Forças de Porter}

Pela aplicação da ferramenta Análise das 5 Forças de Porter, foi possível caracterizar a relação da empresa com os seus clientes, fornecedores, concorrentes, além da ameaça de novos entrantes no mercado e produtos substitutos.

A gama de clientes da empresa está localizada na região da cidade de Amambai, porém as propriedades onde se concentra os produtos é localizada em áreas rurais, algumas em localidades mais próximas outras mais distantes em média de 20 à 60 kg da empresa destino onde irá ser entregue o produto. A faixa etária dos clientes de 35 a 65 anos de idade, com alguns casos mais raros de herdeiros mais novos. A maior parte são homens, com idade media de 50 anos. Os clientes moram na cidade, mas possuem área de atuação no meio agrícola, especificamente na produção de grãos.

A região de entorno possui duas culturas fortes, a soja e o milho, consequentemente a empresa conta com a colheita dos mesmo em duas épocas do ano. No entanto, os clientes trabalham o ano inteiro na produção dessas duas culturas, para que na colheita a empresa em destaque preste seu serviço. Comumente esses produtores rurais, são responsáveis pela supervisão do trabalho de seus funcionários, onde eles possuem em sua propriedade pessoas capacitadas para desenvolver os serviços de antes da porteira e depois da porteira, contudo eles estão sempre monitorando para que haja uma boa produção.

A comercialização desses grãos pode ser feita por intermédio da empresa, que também compra de seus clientes os produtos armazenados, porque é de interesse dos proprietários para consumo animal, ou também por venda direta, do produtor para a empresa que comprou o produto. Atualmente o preço para armazenar os grãos correspondem a uma taxa de recebimento, e possui outro valor, que corresponde com tempo armazenado do produto que por ventura fica recebendo os devidos cuidados para garantir a qualidade.

Um grande diferencial que a empresa possui é a forma de receber e atender os clientes, desde os produtores aos servidores dos produtores, a empresa sempre se preocupando com o bom atendimento, sempre presando que seus clientes se sintam bem ao estarem ali, esse item é de extrema importância para os gerenciadores da organização, sempre em reuniões é mencionado a importância do bem estar dos clientes. Um outro grande fator de vantagem da empresa é a facilidade de comercialização já que eles também atuam como fortes compradores dos produtos para seus clientes, evidenciando uma posição confortável da empresa com os clientes. 
No setor agrícola de cereais há grandes cooperativas armazenadoras. Essas empresas atuam diretamente como concorrentes fortes no mercado, inclusive tendo como diferencial o fato de fornecer insumos para os produtores e, em troca, os produtores devolvem na maioria das vezes como forma de pagamento uma quantidade em sacas de grãos no valor correspondente ao valor adquirido aos insumos.

Estas empresas concorrentes atuam há anos no mercado trabalhando para o reconhecimento e fidelidade dos clientes, por tanto já tem uma rede de clientes fiéis. Além disso, as cooperativas fornecem insumos para a produção.

Entretanto, mesmo com a forte concorrência e pouco tempo de atuação já possui uma grande linha de clientes. Para que os clientes conheçam o armazém, tem sido feito uma estratégia de prestação de serviços para duas cooperativas das cidades, sendo assim ambas as partes são favorecidas, a cooperativa por ter uma aliada ao ter mais espaço para depositar seus produtos fazendo assim um contrato com a empresa, garantindo um lucro fixo para a organização.

A localização é um fator de extrema importância nesse ramo, pois uma rede armazenadora não pode estar localizada no centro da cidade, pois seria extremamente fora de acesso aos produtores, sabendo que o principal foco é as fazendas onde é produzido os grãos, portanto é estratégia que os receptores de grãos sejam localizados nas saídas das cidades, ou em áreas rurais próximos a fazendas, onde é de fácil acesso aos que entregaram o produto ao armazém.

Os principais produtos substitutos no caso da empresa estudada são os silos bags, que possuem valor muito mais inferior aos silos metálicos, e com qualidade não garantida pois ficam apenas armazenadas em grandes bolsas, assim ficando vulneráveis a intempéries temporais, bichos roedores, e entre outras diversificações de vulnerabilidade, e com poucos recursos para manter a qualidade. Porém é de baixo custo, entretanto o produtor não tenha alternativa é um meio bastante acessível e barato.

Outro grande produto substituto que vem crescendo ao decorrer dos anos, é os silos de fazenda, alguns produtores tem optado por construir silos em suas propriedades, assim é possível que seja armazenado todo o seu produto em sua própria localidade. Os benefícios para quem possui um silo em sua propriedade são imensos, pois o produtor não terá custo algum com taxas de armazenagem, terá apenas o custo para que o produto seja armazenado com qualidade, e para que a qualidade se mantenha ao perpassar o tempo.

É fato que ainda não é muito forte esse meio de silos de fazenda, pois o custo é muito alto, porém se todos os produtores adquirissem esse produto substituto, seria sim um fator de 


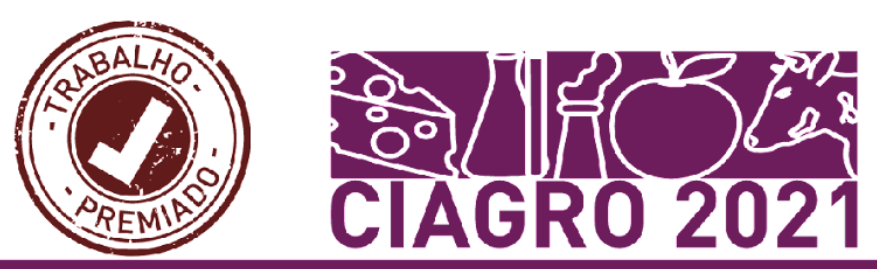

risco para a empresa pois teria muita demanda de armazéns e pouca oferta de produtos para armazenar, se levarmos em conta é um fator de risco se todos adquirissem essa modalidade.

Quanto aos fornecedores, a empresa conta com fornecedores locais e não possui dependência de somente um fornecedor, pois os produtos necessários são de fácil acesso. Então as compras são feitas por cotação de preços para buscar o melhor lugar com preços mais acessíveis. No que abrange os novos entrantes no mercado, é relevante ressaltar que os armazéns metálicos são de custo elevado e, consequentemente, é alto o investimento para abertura de novos empreendimentos, sendo um aspecto positivo para a empresa.

\section{Discussão da Matiz Swot}

A análise do ambiente interno e externo por meio da Matriz Swot permitiu um diagnóstico detalhado, cujos pontos mais importantes estão destacados na figura 3 .

Figura 3: Principais aspectos destacados na Matriz Swot.

\begin{tabular}{|c|c|c|}
\hline & Aspectos internos & Aspectos externos \\
\hline 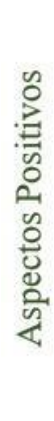 & $\begin{array}{l}\qquad \text { Forças } \\
\text { - Qualidade no atendimento, valorizando a satisfação do cliente. } \\
\text { - Qualidade nos serviços prestados. } \\
\text { - Profissionais capacitados para atuação especifica do negócio. } \\
\text { - Estrutura recente do silo metálico e em perfeitas condições. }\end{array}$ & $\begin{array}{l}\text { Oportunidades } \\
\text { - Região com grande potencial para o agronegócio, vivenciando nos } \\
\text { últimos anos uma expansão da agricultura de precisão, bem como a } \\
\text { abertura de empresas de toda a cadeia do agronegócio na região; } \\
\text { - Os avanços das tecnologias do agronegócio tem trazido formas mais } \\
\text { econômicas e eficazes para os processos de armazenagem e transporte } \\
\text { de grãos; } \\
\text { - Poucas unidades de armazenagem particular na região, predominando } \\
\text { apenas cooperativas. } \\
\text { - Produtores na região com alta produtividade agrícola e necessidade de } \\
\text { escoamento e armazenamento dos grãos. }\end{array}$ \\
\hline 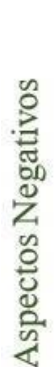 & $\begin{array}{l}\text { - Sistema de informações da empresa com poucos recursos. } \\
\text { - Cultura e identidade empresarial ainda não solidificada, sem definição } \\
\text { de visão, missão e valores. } \\
\text { - Falta de incentivo aos funcionários ou politicas mais estratégicas para } \\
\text { aproveitamento do capital humano. } \\
\text { - Falta de um calador pneumático, para facilitar a classificação dos grãos. }\end{array}$ & $\begin{array}{l}\text { - Predominância e tradicionalismo das cooperativas de insumos na região, } \\
\text { sendo uma forte concorrência. } \\
\text { - Sazonalidade e oscilação dos preços dos grãos, podendo trazer } \\
\text { insegurança na comercializaçãa. } \\
\text { - Dependência de aspectos climáticos e da gestão agrícola dos produtores } \\
\text { para obtenção de boa safra com consequente bom preço e qualidade dos } \\
\text { grãos. }\end{array}$ \\
\hline
\end{tabular}

Fonte: Dados da pesquisa.

Observando a figura 3, observa-se que a empresa possui como principais forças a qualidade no atendimento e nos serviços prestado, além de boa infraestrutura e disponibilidade de recursos para continuar se desenvolvendo. Para garantir que essa infraestrutura esteja sempre em boas qualidades é necessário que seja feito a manutenção dele periodicamente assim 


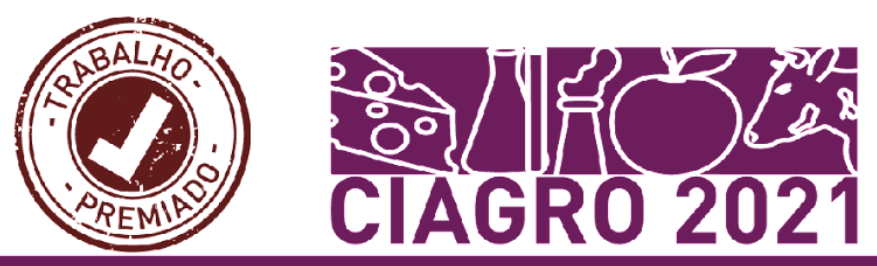

garantindouma maior durabilidade do mesmo. Também destaca-se como ponto positivo do cenário interno a qualificação dos funcionários, uma vez que todos os funcionários possuem capacitação para executar os serviços que lhes cabem.

Entre os aspectos internos negativos mais relevantes destaca-se o sistema de informações da empresa, pois o programa utilizado conta com poucos recursos e escassas atualizações, possuindo inclusive alguns itens básicos e necessários, porém inoperantes.

Já as oportunidades que mais se destacaram são o crescimento do agronegócio da região e o fortalecimento da cadeia produtiva como um todo, permitindo que a empresa tenha suporte e os parceiros necessários. De fato, a região sudoeste do Mato Grosso do Sul tem tido desenvolvimento voltado ao agronegócio, os grandes avanços da tecnologia no setor do agronegócio, e terras com grandes potenciais agricultáveis na região. Esses avanços tem ajudado a evitar desperdícios de insumos e garantir a qualidade das safras, tendo como grande aliado as tecnologias de precisão, que vem assessorando através de coleta de dados, assim melhorando o potencial produtivo. O potencial da qualidade das terras na região é uma ótima chance de o mercado de armazenagem crescer, pois quanto mais produto, maior será a receptividade dos armazéns, além das terras já possuírem alto índice produtivo, as deficiências são preenchidas através da agricultura de precisão, sendo assim cada vez mais a qualidade da produção vem se aprimorando.

Quanto as ameaças, destaca se a forte concorrência sofrida por parte das cooperativas, que juntamente com o serviço de armazenamento, costumam fornecer insumos para os produtores, fortalecendo a relação com o produtor. Entretanto, a política das cooperativas também infligem diversos pontos negativos como a falta de flexibilidade e valores de compra pré-determinado, que são desfavoráveis para produtores rurais que busquem mais autonomia. Alem disso, nada impede que a empresa foco deste estudo adote estratégia de prevenção a essa concorrência, colocando em prática ações que fidelizem os produtores e os ajude a ter mais segurança. Com base em todas essas observações, constata-se que a análise feita apresenta uma atuação positiva da empresa, pois de acordo com os dados levantados na pesquisa, a posição atual que ela se encontra no mercado é positivo, isso significa que ela possui muitos aspectos favoráveis que poderão contribuir para o desenvolvimento da mesma.

\section{Prospecção de Cenários e Escolha Estratégica}

Considerando o resultado das ferramentas aplicadas, é possível estimar alguns cenários possíveis para a empresa. De forma sintética é possível prever que a empresa, sustentada pelo 


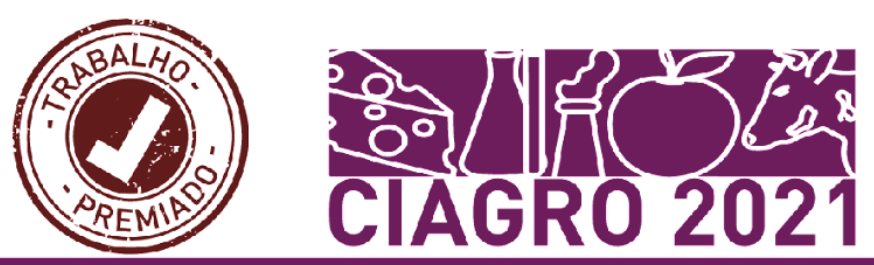

bom atendimento prestado aos clientes e pelo pessoal capacitado, tem condições de continuar acompanhando o desenvolvimento do agronegócio no Mato Grosso do Sul. Entretanto, para evitar as ameaças mais impactantes do cenário atual da empresa, é imprescindível que ela continue investindo em soluções tecnológicas para competir de forma vantajosa com os concorrentes deste mercado tão dinâmico. Além disso, é preciso estar atenta as novas tecnologias específicas às atividades da empresa.

Por conseguinte, os resultados deste estudo parecem indicar que a estratégia de crescimento, que é atualmente empregada pela empresa, seja de fato a mais adequada, uma vez que permitirá que a empresa faça uso dos ganhos atuais para investimentos em atividades futuras e aumentem sua capacidade de atendimento. Nesse sentido, é preciso manter um olhar ainda mais vigilante na qualidade dos serviços e do capital humano disponível para a empresa.

A estratégia de crescimento envolve a expansão da empresa e implica na capacidade dearcar com esse crescimento sem afetar a qualidade de seus serviços. Além disso, essa estratégiase baseia no potencial de mercado, com oportunidades a seu favor, como é o caso do agronegócio na região da organização. É notável que a empresa possui grande potencial de crescimento, pois se ela prosseguir na mesma direção poderá aproveitar oportunidades vantajosas e obter importantes resultados futuros.

\section{CONCLUSÃO}

Em virtudes dos fatos mencionados, o objetivo do trabalho foi fazer um estudo de caso da empresa, onde através das ferramentas de planejamento estratégico, Matriz Swot e Análise de 5 forças de Porter foi possível analisar o cenário atual da empresa.

Esses procedimentos metodológicos permitiram que o objetivo fosse alcançado, por meio da avaliação estratégica da empresa. A Análise de 5 forças de Porter permitiu constatar que apesar da grande concorrência na região, ainda sim a empresa se destaca frente a seus concorrentes. Portanto, empresa possui grande potencial de crescimento no mercado, onde através da ferramenta foi possível observarque a organização também possui aspectos de ameaça aos concorrentes.

Por sua vez a Matriz Swot evidenciou os grandes pontos fortes e fracos da empresa, na qual a organização possui indicativos que ressaltam os aspectos positivos que se sobressaem aos negativos onde é possível perceber que a empresa não se encontra em situação prejudicial.

Deste modo a organização se enquadra na estratégia de crescimento na qual o ambiente externo é favorável para que ela possa aproveitar esses aspectos e transforma-los em 
oportunidades. A estratégia de crescimento é a que mais se enquadra devido aos indicadores serem de crescimento sendo que a empresa já possui projetos de ampliação em uma nova região, assim podendo levar seus serviços a outros clientes.

\section{REFERÊNCIAS}

BARROS, A.M. Gerenciamento da produção visando o crescimento da propriedade rural. Disponível em: $<$ http://rehagro.com.br/plus/modulos/noticias/imprimir.php?cdnoticia=2373> Acessoem 04 de Abril de 2012.

BEHNEN, B. Custos do plantio de grãos na fazenda Quero Quero. Pontifícia Universidade Católica de Goiás. Trabalho de Conclusão de Curso. Dezembro de 2020. Disponível em: https://repositorio.pucgoias.edu.br/jspui/handle/123456789/1072

CHIA VENATO, I; SAPIRO, A. Planejamento Estratégico: fundamentos e aplicações. 1. ed. $13^{\circ}$ tiragem. Rio de Janeiro: Elsevier, 2007.

COSTA, L. M.; FILIPPI, A. C. G.; GUARNIERI, P. Sistemas de gerenciamento de armazéns no agronegócio e em condomínios de armazéns rurais no Distrito Federal. Informe Gepec, v. 24, n. 2, 2020. DOI: https://doi.org/10.48075/igepec.v24i2.24492

COUTINHO, A. R.; CHAVES, M. O. Estratégia e planejamento de mercado para produtor de arroz irrigado tropical. In: Embrapa Arroz e Feijão-Artigo em Anais de congresso (ALICE). In: CONGRESSO BRASILEIRO DE ARROZ IRRIGADO, 6., 2009, Porto Alegre. Estresses e sustentabilidade: desafios para a lavoura arrozeira: anais. Porto Alegre: Sosbai, 2009., 2009.

DUARTE, F. Planejamento Estratégico: uma contribuição para análise de resultados de implantação da média indústria, 2002. 95f. Tese (Curso de Pós-Graduação) - Programa de Revista Perspectiva em Gestão, Educação \& Tecnologia, v.4 n.8, julho-dezembroo/2015 Pós- Graduação em Administração de Empresas, Departamento ECA,Universidade de Taubaté 2002. Disponível em: . Acesso em: 27 maio 2012.

GASPERIN, A. R. Competitividade da agricultura familiar na região central do Rio Grande doSul: um estudo de caso utilizando a Matriz Swot. Dissertação de Mestrado. UFMS. 2017.

KOTLER, P.- Administração de Marketing - 10ª Edição, $7^{\mathrm{a}}$ reimpressão - Tradução Bazán Tecnologia e Lingüística; revisão técnica Arão Sapiro. São Paulo: Prentice Hall, 2000.

MARTINS, L. Marketing: Como se tornar um profissional de sucesso. 1. ed. São Paulo: Digerati Books, 2006.

MARTINEZ, L. F. Uma proposta de ampliação do método de planejamento estratégico no agronegócio (ChainPlan) a partir de uma abordagem de sustentabilidade. Tese de Doutorado. Universidade de São Paulo. São Paulo: 2020. DOI: https://doi.org/10.11606/D.96.2020.tde- 26062020-142250 
MATTOS, P.; RODRIGUES, R. G.; Gomes, M A.; MATTOS, P.;GOLlO, S. S. O desenvolvimento do diagnóstico estratégico em propriedades rurais do agronegócio: análise ambiental em uma propriedade rural familiar. Revista InGEPRO. vol. 02, n. 06, 2010

OLIVEIRA, Djalma de Pinho Rebouças de. Planejamento estratégico: conceitos metodologias, prática. 23. ed. São Paulo: Atlas, 2007.

PEDROZO, E. Á.; BEGNiS, H. S. M.; ESTIVAlETE, V. F. B. Análise do ambiente competitivo como determinante das escolhas estratégicas no agronegócio: um estudo de caso em uma unidade de produção. Contexto. Porto Alegre. Vol. 5, n. 8 (2. sem. 2005), p. 71-96, 2005.

POLACINSKI, E., GESSI, N. L., ABEGG, D. R., WIETHOLTER, D. L., LAZZARETTI, L. A. F., ESPANHOL, D. D., WALKER, R. Inovação e sustentabilidade no agribusiness: uma proposta de aplicação de plataformas digitais. Brazilian Journal of Development, v. 7, n. 1, p. 7658-7679, 2021.

PORTER, M. E., Estratégia competitiva: técnica para analise de indústria e da concorrência /M. E. Porter; tradução de Elisabeth Maria de Pinho Braga. - 2.ed. - Rio de Janeiro: Elsevier; 2004.

PROENÇA, A. Dinâmica estratégica sob uma perspectiva analítica: reinando o entendimento gerencial. Rio de Janeiro: Universidade Cândido Mendes, ARCHÉ, 1999. ano VIII, n. 23.

SERRA, F.; TORRES, M. C. S. \& TORRES, A. P. Administração Estratégica. Rio de Janeiro: Reichmann e Affonso Editores, 2004.OLIVEIRA, Djalma de Pinho Rebouças de Planejamento estratégico: conceitos, metodologia e práticas. In: Planejamento estratégico: conceitos, metodologia e práticas. 2002. p. 337-337.

SILVA, Devanildo Braz da; PEREIRA, Marlos da Silva; SPROESSER, Renato Luiz. O planejamento estratégico como ferramenta para obter vantagem competitiva no agronegócio. Anais do Encontro Científico de Administração, Economia e Contabilidade, v. 1, n. 1, 2011.

SILVA, N., A., C; Planejamento Estratégico no Suporte Gerencial de Pequenas Propriedades Rurais. Trabalho de Conclusão de Curso. Especialização em Gestão do Agronegócio. UFPR. Curitiba; 2018.

SOARES, Danilo de Medeiros Arcanjo et al. O planejamento estratégico na apicultura: uma contribuição para a sustentabilidade. Informativo Técnico do Semiárido, v. 10, n. 2, p. 2630, 2016.

SOUZA, G. M.; AMBONI, N.; ORSSATTO, J. H. C. Planejamento Estratégico no Agronegócio: proposta de aplicação em uma empresa de Santa Catarina. Revista Espacios, v. 38, n. 3, 2017.

SERTEK, P.; GUINDANI, A.R.; MARTINS, S.T. Administração e Planejamento Estratégico. 20. ed. Curitiba: Ibpex, 2007. 131 p. 